\title{
Sleep during the third trimester of pregnancy: the role of depression and anxiety
}

\author{
N. Ruiz-Robledillo ${ }^{\mathrm{a} *}$, C. Canário ${ }^{\mathrm{b}}$, C.C. Dias ${ }^{\mathrm{b}}$, L. Moya-Albiol $^{\mathrm{a}}$ and B. Figueiredo ${ }^{\mathrm{b}}$ \\ ${ }^{a}$ Faculty of Psychology, Department of Psychobiology, University of Valencia, Avenida Blasco \\ Ibañez, 21, 46010 Valencia, Spain; ${ }^{b}$ School of Psychology, Department of Applied Psychology, \\ University of Minho, Gualtar Braga, Portugal
}

(Received 4 July 2014; accepted 3 February 2015)

\begin{abstract}
Depression has been associated with sleep disturbances in pregnancy; however, no previous research has controlled the possible confounding effect of anxiety on this association. This study aims to analyze the effect of depression on sleep during the third trimester of pregnancy controlling for anxiety. The sample was composed by 143 depressed $(n=77)$ and non-depressed $(n=66)$ pregnant women who completed measures of depression, anxiety, and sleep. Differences between groups in sleep controlling for anxiety were found. Depressed pregnant women present higher number of nocturnal awakenings and spent more hours trying falling asleep during the night and the entire $24 \mathrm{~h}$ period. Present findings point out the effect of depression on sleep in late pregnancy, after controlling for anxiety.
\end{abstract}

Keywords: pregnancy; sleep; depression; anxiety

\section{Introduction}

Sleep disturbances during pregnancy have been widely demonstrated in previous research (Hedman, Pohjasvaara, Tolonen, Suhonen-Malm, \& Myllylä, 2002; Mindell \& Jacobson, 2000; Pien \& Schwab, 2004; Santiago, Nolledo, Kinzler, \& Santiago, 2001). Pregnant women experience frequent night awakenings, difficulties falling asleep, and restless and fragmented sleep (Hedman et al., 2002; Mindell \& Jacobson, 2000). Third trimester has been pointed out as the period in which women show the worst sleep (Pien \& Schwab, 2004; Santiago et al., 2001): high frequency of nocturnal awakenings and decrease of subjective sleep quality (Hedman et al., 2002; Santiago et al., 2001). Night waking is considered the main sleep problem in this period (Santiago et al., 2001). However, few studies have investigated the effect of psychological symptoms in sleep during pregnancy, and almost all of them have only considered depression (Field et al., 2007; Kamysheva, Skouteris, Wertheim, Paxton, \& Milgrom, 2010; Okun, Kiewra, Luther, Wisniewski, \& Wisner, 2011; Qiu, Gelaye, Fida, \& Williams, 2012; Skouteris, Germano, Wertheim, Paxton, \& Milgrom, 2008). Additionally, to our knowledge, none of these studies has addressed the possible comorbid effect of anxiety in sleep during pregnancy, although the effect of anxiety has been extensively showed in other periods (e.g. Uhde, Cortese, \& Vedeniapin, 2009).

More studies are needed to clarify the effect of depression on sleep after controlling for the comorbid effect of anxiety. This study aimed to analyze the association between

*Corresponding author. Email: Nicolas.Ruiz@uv.es 
depression and sleep during the third trimester of pregnancy, controlling for the possible effect of anxiety. We expect to find high sleep disturbances in depressed pregnant compared to non-depressed (Field et al., 2007; Kamysheva et al., 2010; Okun et al., 2011; Qiu et al., 2012; Skouteris et al., 2008), after controlling for anxiety.

\section{Method}

\section{Participants}

The sample was recruited at the third pregnancy trimester in two Public Outpatient Hospital Units in Portugal. Exclusion criteria were not reading or writing Portuguese, multiple gestations and medical complications (e.g. gestational diabetes, placental abruption, gestational hypertension). A total of 143 women participated in the study.

Sociodemographic data for all participants are summarized in Table 1.

\section{Measures}

Edinburgh Postnatal Depression Scale (EPDS)

The Portuguese version (Augusto, Kumar, Calheiros, Matos, \& Figueiredo, 1996) of the Edinburgh Postnatal Depression Scale (EPDS) (Cox, Holden, \& Sagovsky, 1987) was employed to evaluate symptoms of depression within the previous seven day. This questionnaire is a self-report measure composed of 10 items scored on a four-point Likert scale. Higher scores indicate higher depression symptomatology. Cronbach's alpha in this study was .83 .

\section{State Anxiety Inventory (STAI-S)}

The Portuguese version (Biaggio, Natalicio, \& Spielberger, 1976) of the State Anxiety Inventory (Spielberger, Gorsuch, Lushene, Vagg, \& Jacobs, 1983) (STAI-S) was used to evaluate current anxiety. The inventory is composed of 20 items ranked by means of a four-point Likert scale. Higher scores indicate higher state anxiety. Cronbach's alpha in this study was .93 .

Table 1. Sociodemographic variables for depressed and non-depressed pregnant women separately.

\begin{tabular}{|c|c|c|c|c|}
\hline & & Depressed $(n=66)$ & Non-depressed $(n=77)$ & $p$ \\
\hline Age & & $31.27 \pm 5.45$ & $31.22 \pm 4.38$ & .959 \\
\hline \multirow[t]{3}{*}{ Schooling (years) } & $<12$ & $15.2 \%$ & $5.2 \%$ & \multirow[t]{3}{*}{.027} \\
\hline & 12 & $36.4 \%$ & $27.3 \%$ & \\
\hline & $>12$ & $47 \%$ & $66.2 \%$ & \\
\hline \multirow[t]{3}{*}{ Marital status } & Single & $23.4 \%$ & $12.5 \%$ & \multirow[t]{3}{*}{.246} \\
\hline & Married & $53.1 \%$ & $59.7 \%$ & \\
\hline & Cohabiting & $23.4 \%$ & $27.8 \%$ & \\
\hline \multirow[t]{2}{*}{ Occupational status } & Employed & $71.2 \%$ & $77.9 \%$ & \multirow[t]{2}{*}{.421} \\
\hline & Unemployed & $22.7 \%$ & $13 \%$ & \\
\hline \multirow[t]{2}{*}{ Parity } & Primiparous & $51.5 \%$ & $66.2 \%$ & \multirow[t]{2}{*}{.103} \\
\hline & Multiparous & $40.9 \%$ & $27.3 \%$ & \\
\hline
\end{tabular}




\section{Sleep chronogram}

The sleep chronogram is a self-reported measure to account for sleeping, awaking, or falling asleep, in periods of $30 \mathrm{~min}$ during $24 \mathrm{~h}$ (from $8 \mathrm{am}$ of the day before to $8 \mathrm{am}$ of the present day). The day period was defined from 8 am to $8 \mathrm{pm}$, and the night period from $8 \mathrm{pm}$ to $8 \mathrm{am}$. According to the participants' report, the following variables were obtained: hours sleeping during the night, hours sleeping during the day, hours sleeping during the period of $24 \mathrm{~h}$, hours falling asleep during the night, hours falling asleep during the day, hours falling asleep during the period of $24 \mathrm{~h}$, and awakenings during the night. The sleep chronogram aims to be a reliable self-report of sleep and was developed for the current research.

\section{Procedure}

Ethical Commission of the two Public Outpatient Hospital Units where the recruitment took place approved the research protocol (The Ethical Commission of Centro Hospitalar do Porto on September 202012 and the Ethical Commission of Hospital de Braga on October 17 2012). Pregnant women in the third gestational trimester (30-40 weeks) were invited to participate and informed about the purposes and procedure of the study. Women who accepted to participate (92\% of the contacted women) signed an informed consent and completed the sociodemographic questionnaire, the EPDS, the STAI-S, and the sleep chronogram. The sleep chronogram was filled in the morning, and the participants were explained to register their sleep behavior during one entire day (from 8 am of the day before to 8 am of the present day).

\section{Statistical analyses}

Women were classified in two groups based on the EPDS scores ( $\geq 9$ for depressed and $<9$ for non-depressed), following author's instructions (Tendais, Costa, Conde, \& Figueiredo, 2014). Multivariate analysis of covariance was performed to evaluate the effect of depression on the number of awakenings during the night, and the number of hours sleeping and falling asleep during the day and night. The effect of depression on the number of hours sleeping and falling asleep during the period of $24 \mathrm{~h}$ was assessed performing univariate analysis of covariance. In these analyses, STAI-S scores were included as a covariate to control for possible effect of anxiety on the results. Statistical significance was defined as $p<.05$, and the effect-size measure partial eta squared $\left(\eta_{p}^{2}\right)$ was estimated for all analyses of variance.

\section{Results}

\section{The multivariate effect of depression on sleep, with anxiety as a covariate}

A marginally significant multivariate effect of anxiety was found for sleep (Wilks' Lambda $\left.=.933, F(5,136)=1.943, p=.091, \eta_{p}^{2}=.067\right)$. When controlling for anxiety, a significant multivariate effect of depression was found for sleep (Wilks' Lambda $=.896$, $\left.F(5,136)=3.150, p=.010, \eta_{p}^{2}=.104\right)$. Tests of between-subject effects, controlling for anxiety, revealed a significant univariate effect of depression on the number of awakenings during the night $\left(F(1,140)=7.367, p=.007, \eta_{p}^{2}=.050\right)$ and on the number of hours trying to fall asleep during the night $\left(F(1,140)=4.859, p=.029, \eta_{p}^{2}=.034\right)$. When controlling for anxiety, depressed women revealed a higher number of awakenings (mean 
difference $=.510)$ and of hours spent trying to fall asleep (mean difference $=.563$ ) during the night (Table 2).

\section{The univariate effect of depression on number of hours sleeping and trying to fall asleep during the period of $24 \mathrm{~h}$, with anxiety as a covariate}

When controlling for anxiety, no significant effect of depression was found for the number of hours sleeping during the period of $24 \mathrm{~h}(F(1,140)=.085, p=.771)$.

A significant effect of depression was found for the number of hours trying to fall asleep during the period of $24 \mathrm{~h}\left(F(1,140)=4.254, p=.041, \eta_{p}^{2}=.040\right)$. When controlling for anxiety, depressed women revealed a higher number of hours spent falling asleep during the period of $24 \mathrm{~h}$ (mean difference $=.593)$ (Table 3$)$.

\section{Discussion}

Results showed significant differences between depressed and non-depressed pregnant women in sleep during the third trimester of pregnancy, when anxiety was controlled. Depressed pregnant women presented higher number of awakenings during the night and spent more hours trying to fall asleep at night and during the period of $24 \mathrm{~h}$, compared to non-depressed pregnant women. These results provide evidence that depression has a negative effect in sleep during late pregnancy, after controlling for the possible effect of anxiety.

Sleep disturbances during late pregnancy are mainly characterized by the increased number of awakenings during the night, compared to the earlier trimesters (Mindell \& Jacobson, 2000; Santiago et al., 2001). Our results revealed that depression could pronounce this sleep disruption, increasing even more the number of night awakenings. Additionally, our results indicate that depressed pregnant women report more difficulties to fall asleep at night and during the period of $24 \mathrm{~h}$. In this regard, previous research found that the difficulty of falling asleep was the only significant predictor for depressive symptomatology in pregnant women (Swanson, Pickett, Flynn, \& Armitage, 2011). Problems falling asleep are particularly relevant also taking into account that they were identified as an important predictor of postpartum depression in new mothers (Goyal, Gay, \& Lee, 2007). Normative physiological and hormonal changes during pregnancy may be intensified by mood disorders and configure the mediator effect of depression on sleep disturbances (Qiu et al., 2012).

Table 2. Differences between depressed and non-depressed pregnant women in the outcome sleep variables separately for day and night.

\begin{tabular}{lccc}
\hline & $\begin{array}{c}\text { Depressed } \\
\text { women } \\
(n=66), M(\mathrm{SD})\end{array}$ & $\begin{array}{c}\text { Non-depressed } \\
\text { women } \\
(n=77), M(\mathrm{SD})\end{array}$ & $\begin{array}{c}F \\
(1,140)\end{array}$ \\
Number of & $1.23(1.23)$ & $.81(.89)$ & $7.37^{* *}$ \\
\hline Awakenings during the night & $6.56(1.61)$ & $6.71(2.12)$ & .01 \\
Hours sleeping during the night & $1.74(1.51)$ & $1.09(1.36)$ & $4.859^{*}$ \\
$\begin{array}{l}\text { Hours trying to fall asleep during the } \\
\text { night }\end{array}$ & $.98(1.43)$ & $1.06(1.42)$ & .31 \\
Hours sleeping during the day & $.23(.69)$ & $.24(.46)$ & .09 \\
Hours trying to fall asleep during the day & &
\end{tabular}

Notes: Wilks' Lambda $=.896, F(5,136)=3.150, p=.010, \eta_{p}^{2}=.104$. Anxiety entered the model as a covariate. $* p<.05 ; * * p<.01$. 
Table 3. Differences between depressed and non-depressed pregnant women in the hours slept during $24 \mathrm{~h}$.

\begin{tabular}{lccc}
\hline Number of & $\begin{array}{c}\text { Depressed women } \\
(n=66), M(\mathrm{SD})\end{array}$ & $\begin{array}{c}\text { Non-depressed women } \\
(n=77), M(\mathrm{SD})\end{array}$ & $F(1,140)$ \\
\hline $\begin{array}{l}\text { Hours sleeping during the period of } 24 \mathrm{~h} \\
\begin{array}{l}\text { Hours trying to fall asleep during } \\
\text { the period of } 24 \mathrm{~h}\end{array}\end{array}$ & $7.55(2.04)$ & $7.78(2.50)$ & .09 \\
\hline
\end{tabular}

Note: Anxiety entered the model as a covariate.

$* p<.05$.

Due to the high comorbidity between anxiety and depression during pregnancy (e.g. Figueiredo \& Conde, 2011) and the effect of both on sleep, controlling for anxiety while addressing the effect of depression constitutes an advance with regard to previous research. Some limitations have to be addressed. The sleep chronogram gives us an extended self-report of different aspects of sleep. However, the report was for only one day that may be not a typical day. As any self-report, the sleep chronogram report was influenced by the participant's mood. Other sleep measures such as actigraphy or polysomnography could provide more information to reinforce the obtained results. It would also be necessary to analyze sleep in several moments in order to evaluate the effect of depression and anxiety on sleep, considering the bidirectional effects between these variables.

\section{Funding}

This research was supported by FEDER Funds through the Programa Operacional Factores de Competitividade - COMPETE and by National Funds through FCT - Fundação para a Ciência e a Tecnologia under the project: PTDC/SAU/SAP/116738/2010.

\section{References}

Augusto, A., Kumar, R., Calheiros, J. M., Matos, E., \& Figueiredo, E. (1996). Post-natal depression in an urban area of Portugal: Comparison of childbearing women and matches controls. Psychological Medicine, 26, 135-141.

Biaggio, A. M., Natalicio, L., \& Spielberger, C. D. (1976). The development and validation of an experimental Portuguese form of the State-Trait Anxiety Inventory. In C. D. Spielberger \& R. Dias-Guerrero (Eds.), Cross-cultural research on anxiety (pp. 29-40). Washington, DC: Hemisphere/Wiley.

Cox, J. L., Holden, J. M., \& Sagovsky, R. (1987). Detection of postnatal depression: Development of the 10-item Edinburgh depression scale. British Journal of Psychiatry, 150, 782-786.

Field, T., Diego, M., Hernandez-Reif, M., Figueiredo, B., Schanberg, S., \& Kuhn, C. (2007). Sleep disturbances in depressed pregnant women and their newborns. Infant Behavior and Development, 30, 127-133.

Figueiredo, B., \& Conde, A. (2011). Anxiety and depression in women and men form early pregnancy to 3-months postpartum. Archive of Women's Mental Health, 14, 247-255.

Goyal, D., Gay, C. L., \& Lee, K. A. (2007). Patterns of sleep disruption and depressive symptoms in new mothers. The Journal of Perinatal and Neonatal Nursing, 21, 123-129.

Hedman, C., Pohjasvaara, T., Tolonen, U., Suhonen-Malm, A. S., \& Myllylä, V. V. (2002). Effects of pregnancy on mothers' sleep. Sleep Medicine, 3, 37-42.

Kamysheva, E., Skouteris, H., Wertheim, E. H., Paxton, S. J., \& Milgrom, J. (2010). A prospective investigation of the relationships among sleep quality, physical symptoms, and depressive symptoms during pregnancy. Journal of Affective Disorders, 123, 317-320. 
Mindell, J. A., \& Jacobson, B. J. (2000). Sleep disturbances during pregnancy. Journal of Obstetric, Gynecologic \& Neonatal Nursing, 29, 590-597.

Okun, M. L., Kiewra, K., Luther, J. F., Wisniewski, S. R., \& Wisner, K. L. (2011). Sleep disturbances in depressed and nondepressed pregnant women. Depression and Anxiety, 28, 676-685.

Pien, G. W., \& Schwab, R. J. (2004). Sleep disorders during pregnancy. Sleep, 27, 1405-1417.

Qiu, C., Gelaye, B., Fida, N., \& Williams, M. A. (2012). Short sleep duration, complaints of vital exhaustion and perceived stress are prevalent among pregnant women with mood and anxiety disorders. BMC Pregnancy \& Childbirth, 12(104), 1-9.

Santiago, J. R., Nolledo, M. S., Kinzler, W., \& Santiago, T. V. (2001). Sleep and sleep disorders in pregnancy. Annals of Internal Medicine, 134, 396-408.

Skouteris, H., Germano, C., Wertheim, E. H., Paxton, S. J., \& Milgrom, J. (2008). Sleep quality and depression during pregnancy: A prospective study. Journal of Sleep Research, 17, 217-220.

Spielberger, C. D., Gorsuch, R. L., Lushene, R., Vagg, P. R., \& Jacobs, G. A. (1983). Manual for the state-trait anxiety inventory. STAI (Form Y). Self evaluation questionnaire. Palo Alto: Consulting Psychologists Press.

Swanson, L. M., Pickett, S. M., Flynn, H., \& Armitage, R. (2011). Relationships among depression, anxiety, and insomnia symptoms in perinatal women seeking mental health treatment. Journal of Women's Health, 20, 553-558.

Tendais, I., Costa, R., Conde, A., \& Figueiredo, B. (2014). Screening for depression and anxiety disorders from pregnancy to postpartum with the EPDS and STAI. Spanish Journal of Psychology, 17(e7), 1-9.

Uhde, T. W., Cortese, B. M., \& Vedeniapin, A. (2009). Anxiety and sleep problems: Emerging concepts and theoretical treatment implications. Current Psychiatry Reports, 11, 269-276. 